\title{
Morphological Modification for Optimum Electrochemical Performance of Highly Pristine Polypyrrole Flexible Electrodes, via SILAR Immersion Time and Fabrication of Solid State Symmetric Device
}

\author{
A.V. Thakur and B.J. Lokhande* \\ Lab of Electrochemical Studies, School of Physical Sciences, \\ Solapur University, Solapur 413 255, M.S., India
}

Received August 14, 2017; accepted January 10, 2018

\begin{abstract}
In the chemical synthesis of polypyrrole (PPy), pyrrole oxidative polymerization was done. The use of alkali salts viz. $\mathrm{FeCl}_{3}, \mathrm{Fe}\left(\mathrm{NO}_{3}\right)_{3}$, as an oxidative polymerizer, creates impurities, affecting the purity of formed PPy. In this work, highly pristine PPy flexible electrodes (FE) were chemically synthesized using a $0.1 \mathrm{M}$ solution of pyrrole acidified with $0.05 \mathrm{M} \mathrm{HClO}_{4}$ and $30 \mathrm{wt} \% \mathrm{H}_{2} \mathrm{O}_{2}$, by the successive ionic layer adsorption and reaction (SILAR) method. FEs XRD patterns indicate amorphous PPy formation. A characteristic peak at $1559 \mathrm{~cm}^{-1}$ in the FTIR spectra confirms PPy formation. A gradual change in the surface morphology with SILAR immersion time was observed. Nyquist plots describe different impedance parameters, which vary with SILAR immersion times. In cyclic voltammetric analysis (CV), the maximum specific capacitance observed for the FEs prepared with an immersion time of $10 \mathrm{~s}$ was $520.48 \mathrm{Fg}^{-1}$. Specific capacitance calculated using the galvanostatic charge discharge (GCD) analyses was $529.70 \mathrm{Fg}^{-1}$, which was nearly the same as that observed by CV. FEs exhibited great cycling stability, even after 5000 cycles, with $74.43 \%$ of capacitance retention. Solid state symmetric device (SSD) produced specific capacitance as high as $312.28 \mathrm{Fg}^{-1}$, with $76 \%$ of retention, even after 5000 cycles.
\end{abstract}

Keywords: Smart polymers, pristine polypyrrole, SILAR, tailor made polymers and supercapacitor.

\section{Introduction}

Supercapacitors are an indispensable part of today's energy efficient world, as they deliver high power and high energy, as required [1-2]. Energy and power delivered by the supercapacitor depend on the electrode material used for the electrode preparation. Researchers have been synthesizing and testing various electrode materials in pure, as well as composite, forms [3-7]. Ease of synthesis,

\footnotetext{
* Corresponding author. E-mail address: bjlokhande@yahoo.com
} 
low oxidation potential, water soluble monomer, high charge storage ability, and good electrical conductivity are some of polypyrrole's (PPy) distinguishing properties, making it suitable for supercapacitive electrodes [8-10]. PPy conductivity is due to conjugated double bonds, allowing electrons' free movements, making it electrically conducting [9, 11-12]. Literature shows a wide variety of the pristine PPy aqueous route synthesis by pyrrole oxidative polymerization [11, 12, 14-16]. Shinde et al. have synthesized PPy by pyrrole oxidative polymerization, using three different oxidizers viz. $\mathrm{FeCl}_{3},\left(\mathrm{NH}_{4}\right)_{2} \mathrm{~S}_{4} \mathrm{O}_{8}$ and $\mathrm{K}_{2} \mathrm{C}_{\mathrm{r} 2} \mathrm{O}_{7}$ [9], with $\mathrm{H}_{2} \mathrm{SO}_{4}$, to acidify the solutions. However, the use of such oxidizers increases the chances of pristine PPy contamination with oxide and hydroxide metals species [17]. Thus, $\mathrm{H}_{2} \mathrm{O}_{2}$ as an oxidizer is favorable to avoid PPy contamination. Arunas Ramanavicius et al. have demonstrated a model for PPy nano-particles synthesis, using $\mathrm{H}_{2} \mathrm{O}_{2}$ [18]. Further, the chemical combination of $\mathrm{H}_{2} \mathrm{O}_{2}$ and $\mathrm{H}_{2} \mathrm{SO}_{4}$ forms a piranha solution [19-25], which is corrosive and detrimental to organic materials. Hence, it is not possible to synthesize PPy using $\mathrm{H}_{2} \mathrm{O}_{2}$ in $\mathrm{H}_{2} \mathrm{SO}_{4}$ presence. $\mathrm{HClO}_{4}$ provides an acidic $\mathrm{pH}$ nearly equal to 1 , but does not combine with $\mathrm{H}_{2} \mathrm{O}_{2}$ to form any corrosive solution. Hence, it was decided to: (i) grow the pristine PPy films on stainless steel strips by the SILAR method, to produce flexible electrodes (FEs); (ii) study the effect of SILAR immersion time variations on FEs morphological and electrochemical performances, by electrochemically characterizing the prepared FEs using cyclic voltammetry (CV), galvanostatic charge-discharge (GCD) analyses and electrochemical impedance spectroscopy (EIS); and (iii) fabricate a solid state symmetric device (SSD) comprising of FEs with optimized performance, and analyze it by CV.

\section{Experimental \\ Materials}

In the synthesis work, extra pure pyrrole (sigma Aldrich, USA), $\mathrm{HClO}_{4}$ and $30 \mathrm{wt}$ $\%$ of $\mathrm{H}_{2} \mathrm{O}_{2}$ (SD fine chemicals, India) were used as source materials, without any further purifications. $\mathrm{NaNO}_{3}$ (SD fine chemicals, India) was used to prepare the electrolyte. Double distilled water was used as a solvent in all experiments. Polyvinyl-alcohol (PVA) was used to prepare the gel.

\section{Electrode preparation}

All the synthesis and electrochemical characterization work has been carried out at the temperature of $300.15 \mathrm{~K}$, humidity of $18 \%$ and pressure of $1003.0 \mathrm{mb}$.

\section{Substrate pretreatment}

Stainless steel (SS) strips of 304 grade ( $\operatorname{size}=1 \mathrm{~cm} \times 5 \mathrm{~cm} \mathrm{x} 45 \mu \mathrm{m}$ ) were used as conducting substrate material. They were mirror polished using fine polish paper (grade 600), to get the rough finish. These strips were ultrasonicated in double distilled water for $20 \mathrm{~min}$, to remove the dirt, oil, stains, etc., from their surfaces. Further, they were treated with $0.025 \mathrm{M} \mathrm{HNO}_{3}$ for $1 \mathrm{~min}$, to allow the proper electrode material nucleation and growth by adsorption [11-12]. 


\section{SILAR deposition}

All pyrrole solutions were prepared in $0.05 \mathrm{M}$ aqueous $\mathrm{HClO}_{4}$, to maintain the acidic $\mathrm{pH}$. In the pilot study, precursors' variations in molar concentrations were tried. A uniform thin film formation was found for $0.1 \mathrm{M}$ pyrrole and $30 \mathrm{wt} \%$ of $\mathrm{H}_{2} \mathrm{O}_{2}$. Each SILAR cycle involved successive immersions of the SS strip in a 10 $\mathrm{mL}$ aqueous solution of $0.1 \mathrm{M}$ pyrrole and $30 \mathrm{wt} \%$ of $\mathrm{H}_{2} \mathrm{O}_{2}$, for a given immersion time $\left(\mathrm{I}_{\mathrm{t}}\right)$. These strips were pressure cleaned by the jets of double distilled water after each cycle, to remove loosely bound, un-oxidized and partially oxidized radicals. 60 of such SILAR cycles have been carried out. FEs prepared with different $I_{t}$ (immersion time), viz. $10 \mathrm{~s}, 20 \mathrm{~s}, 30 \mathrm{~s}$ and $40 \mathrm{~s}$, were coded as $\mathrm{P}_{10}, \mathrm{P}_{20}, \mathrm{P}_{30}$, and $\mathrm{P}_{40}$, respectively (Table 1).

Table 1. Synthesis parameters for different FEs at $5 \mathrm{mVs}^{-1}$, in $0.5 \mathrm{M} \mathrm{NaNO}_{3}$.

\begin{tabular}{cccc}
\hline \multirow{2}{*}{ FEs } & \multicolumn{2}{c}{ Immersion time $\mathbf{I}_{\mathbf{t}}(\mathbf{s})$} & SILAR cycles \\
\cline { 2 - 3 } & in $\mathbf{0 . 1} \mathbf{M}$ pyrrole & in $\mathbf{3 0}$ wt $\mathbf{~ H}_{\mathbf{2}} \mathbf{O}_{\mathbf{2}}$ & \\
\hline $\mathrm{P}_{10}$ & 10 & 10 & 60 \\
$\mathrm{P}_{20}$ & 20 & 20 & 60 \\
$\mathrm{P}_{30}$ & 30 & 30 & 60 \\
$\mathrm{P}_{40}$ & 40 & 40 & 60 \\
\hline
\end{tabular}

Fabrication of the solid state symmetric device (SSD)

P10 FEs with optimum SC were used to fabricate the SSD. A $0.5 \mathrm{M} \mathrm{NaNO}_{3}$ aqueous solution has been prepared in double distilled water. $1 \mathrm{~g}$ of PVA was dispersed in $50 \mathrm{~mL}$ of double distilled water, and stirred at $348.15 \mathrm{~K}$, to form a gel, until the solution volume was reduced to $20 \mathrm{~mL}$. By slowly adding the $\mathrm{NaNO}_{3}$ solution to PVA gel at $350.15 \mathrm{~K}$, the viscous gel electrolyte was produced. The gel was sandwiched amid FEs. Parchment paper was used as separator to avoid FEs direct contact.

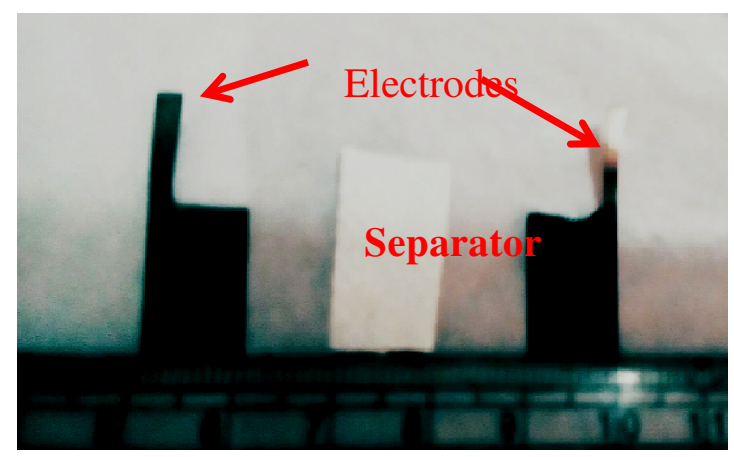

Figure 1. SSD components.

The assembly (Fig. 1) was then sealed with the insulating tape, and pressed in a hydraulic press, to avoid air gaps and leakage. These assemblies are the ones defined as SSDs. 


\section{Characterization}

Physical characterizations

All FEs structural characterizations have been carried out by using different techniques. X-ray diffraction (XRD) patterns obtained by an X-ray diffractometer (Ultima IV Rigaku $\mathrm{D} / \max 2550 \mathrm{Vb}+18 \mathrm{~kW}$ with $\mathrm{CuK} \alpha, \lambda=$ $1.54056 \AA$, Japan), in the diffraction angle $(2 \theta)$ range from $10^{\circ}$ to $90^{\circ}$, were used to study the formed material nature. Fourier transform infra-red (FTIR) patterns, obtained by a FTIR spectrophotometer (Nicolet iS 10, Thermo scientific, USA), were used to verify PPy formation. Field Emission Scanning Electron Microscopy (FESEM) and Elemental Dispersive Spectroscopy (EDS) were carried out by using a scanning electron microscope ((FESEM JEOL JSM$7600 \mathrm{~F}$ HITACHI, Japan), to check the surface morphologies and elemental compositions of prepared FEs. Weight of the deposited material was measured by the weight difference method, using a high accuracy analytical microbalance (Tapson-100TS, USA), with the least count of $10^{-5} \mathrm{~g}$. The surface wettability analyses have been carried out using a contact angle meter (HO-IAD- CAM-01, Holmark opto-mechatronics, India).

\section{Electrochemical characterizations}

FEs electrochemical characterizations have been carried out using an electrochemical analyzer (CHI 408C, USA) with a standard three electrodes cell comprising $\mathrm{FE}$ as working electrode, platinum wire as counter electrode, saturated $\mathrm{Ag} / \mathrm{AgCl}$ as reference electrode and a $20 \mathrm{~mL}$ aqueous solution of 0.5 $\mathrm{M} \mathrm{NaNO}_{3}$ as electrolyte. SSDs were electrochemically analyzed using a standard two electrode configuration. Cyclic voltammetric (CV) curves were used to calculate the specific capacitance (SC) by equations 1 and 2 given in the text. Galvanostatic charge-discharge analyses have been carried out to evaluate chronopotentiometric parameters, using formulae 3, 4, 5 and 6. Electrochemical impedance spectroscopic (EIS) analyses have also been carried out, to find different parameters, viz. electrochemical series resistance (ESR), double layer capacitance $\left(C_{d 1}\right)$, charge transfer resistance $\left(R_{c t}\right)$ and Warburg impedance $\left(R_{w}\right)$.

\section{Results and discussion \\ Film formation mechanism}

Scheme 1 shows FEs formation. In the cationic bath, pyrrole has lost one electron, to form a polaron. Several polarons were adsorbed onto the SS strips, and successively united to form bipolaron, trimer, quinoid structure and finally, PPy. The electrons lost during polarons formation are taken by $\mathrm{H}_{2} \mathrm{O}_{2}$, to form $(\mathrm{OH})^{-}$ions. These species recombine with $\mathrm{H}^{+}$ions, to form water. As there are no other byproducts than water, the formed PPy is 100\% pristine. 


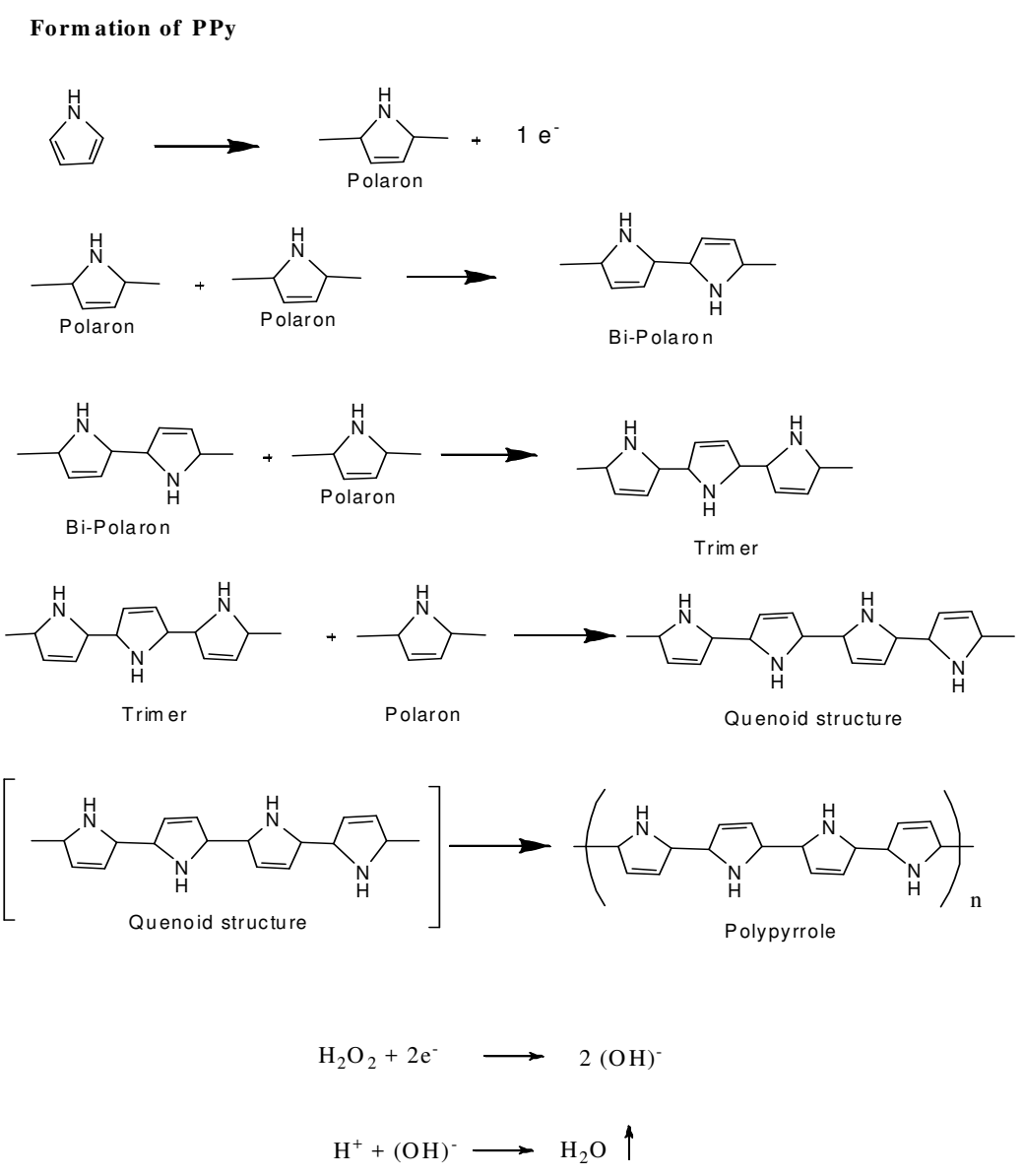

Scheme 1. PPy FE formation.

\section{Structural elucidation}

FEs XRD patterns are shown in Fig. 2A. The characteristic broad peak observed at $2 \theta\left(22^{\circ}\right)$ confirms amorphous PPy formation [13-26], which is due to the Xrays scattering from PPy chains at the interplanar spacing. The average chain separation can be calculated from these maxima, using equation 1 [27-28].

$$
S=\frac{5 \lambda}{8 \sin \theta}
$$

where $S$ is the polymer chain separation, $\lambda$ is the $X$-ray wavelength and $\theta$ is the diffraction angle at the maximum intensity. The average chain separation $(R)$ was found to be 4.38 Á for PPy [29-33]. This enables amorphous PPy formation.

FTIR spectrophotograph of all the prepared FEs (Fig. 2B) demonstrates the peak at the wave number of $1576 \mathrm{~cm}^{-1}$, corresponding to $\mathrm{C}-\mathrm{C}$ and $\mathrm{C}=\mathrm{C}$ skeletal (ring) vibrations. The peak at $1032 \mathrm{~cm}^{-1}$ is due to the $\mathrm{C}-\mathrm{H}$ deformation vibration; the peak at $1185 \mathrm{~cm}^{-1}$ is due to C-N stretching; and the peak at $603 \mathrm{~cm}^{-1}$ is due to the $\mathrm{N}-\mathrm{H}$ wagging; while a broad peak at $2911 \mathrm{~cm}^{-1}$ is due to $\mathrm{N}-\mathrm{H}$ stretching and vibrations. All these peaks confirm PPy formation.

FEs' FESEM images (Fig. 2C) clearly exhibit the transition from globular morphology to the dense mud-like morphology, with an increased $\mathrm{I}_{\mathrm{t}}$. The average globular size for $\mathrm{P}_{10}$ was $100 \mathrm{~nm}$, which went on reducing, as the dense PPy growth occurred with the increased $\mathrm{I}_{\mathrm{t}}$. Finally, for $\mathrm{P}_{40}$, it became $60 \mathrm{~nm}$. 

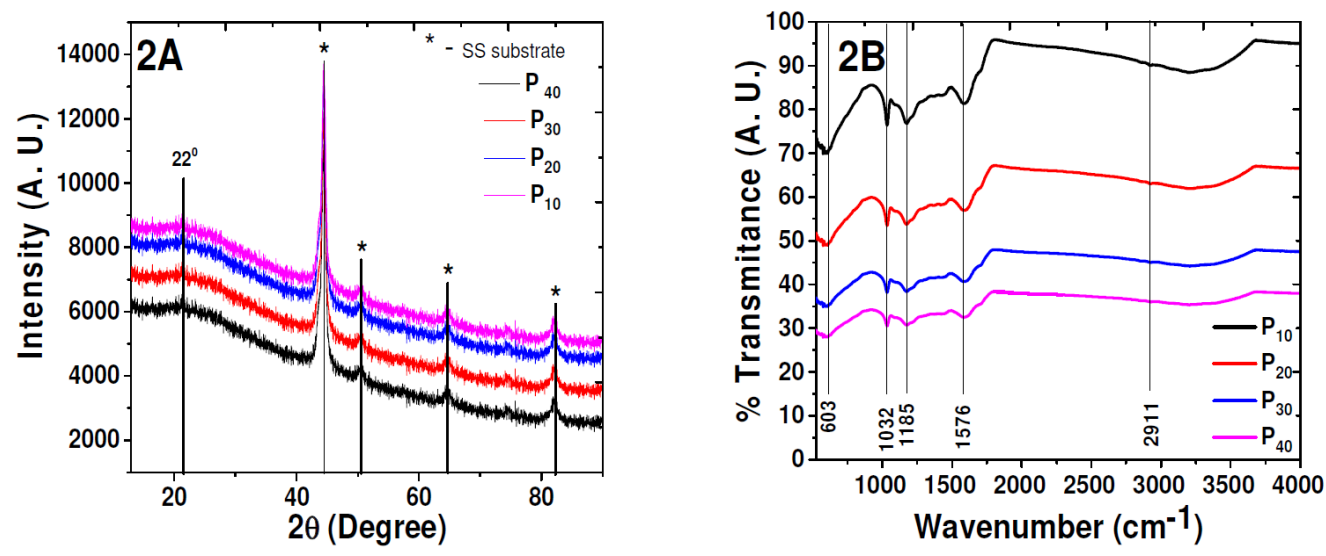

Figure 2. XRD patterns (A) and FTIR spectra (B) of prepared FEs.
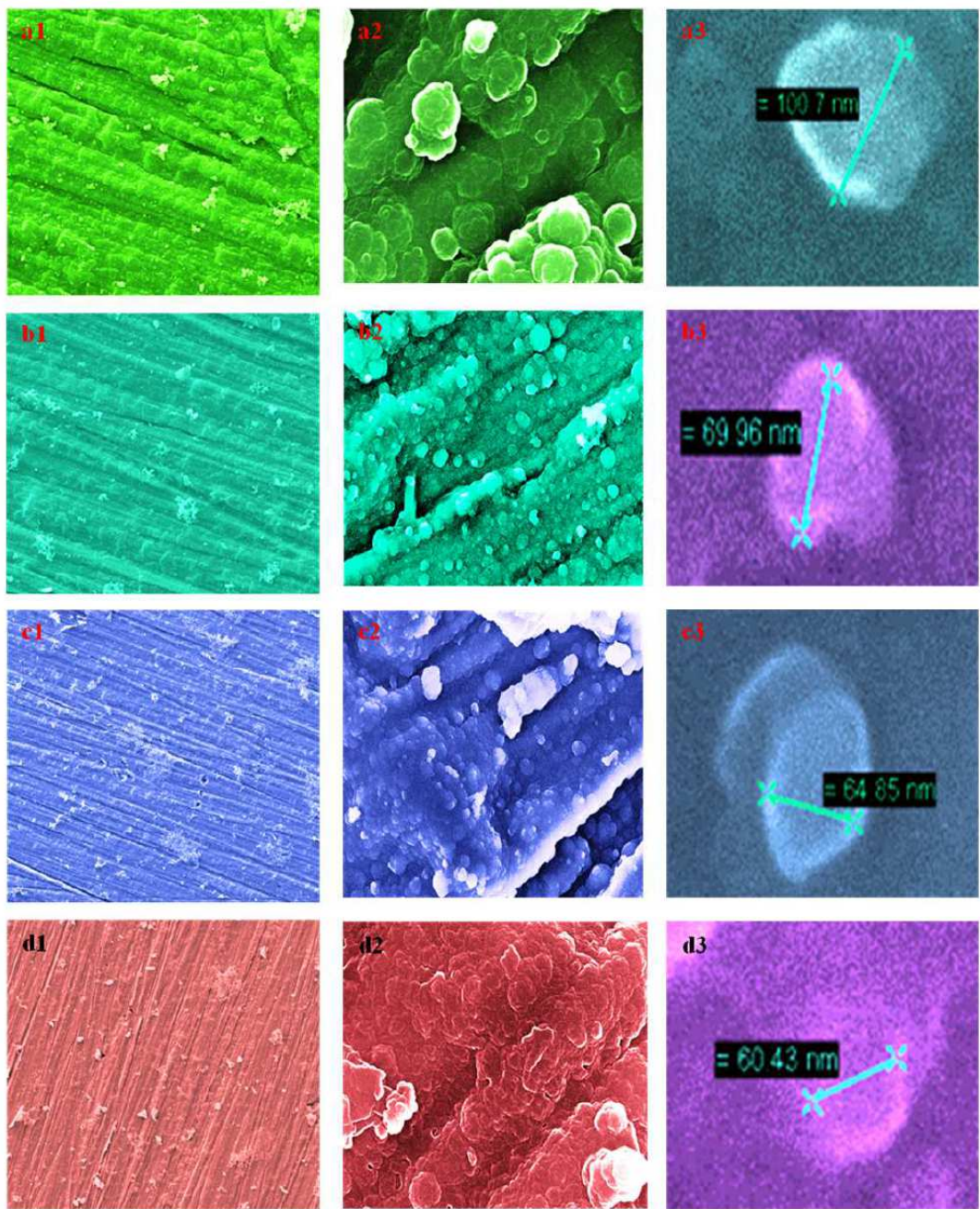

Figure 2C. FEs SEM images: a1) $\mathrm{P}_{10}$, b1) $\mathrm{P}_{20}$, c1) $\mathrm{P}_{30}$ and d1) $\mathrm{P}_{40}$; FEs FESEM images: a2) $\mathrm{P}_{10}$, b2) $\mathrm{P}_{20}$, c2) $\mathrm{P}_{30}$ and d2) $\mathrm{P}_{40}$; and average globular size from FEs FESEM: a3) $\mathrm{P}_{10}$, b3) $\mathrm{P}_{20}$, c3) $\mathrm{P}_{30}$ and d3) $\mathrm{P}_{40}$.

A decrease in the material's film thickness, from $6 \mu \mathrm{m}$ for $\mathrm{P}_{10}$, to $4.02 \mu \mathrm{m}$ for $\mathrm{P}_{40}$, was observed. This confirms the globular size reduction, as the film became more compact with an increased $I_{t}$ (Fig. 2D). The peaks corresponding to $\mathrm{C}, \mathrm{N}$, 
and $\mathrm{O}$ in EDS pattern also substantiated PPy formation (Fig. 2E). Surface wettability studies showed that the material became less hydrophilic with the increased $\mathrm{I}_{\mathrm{t}}$ (Fig. 2F).
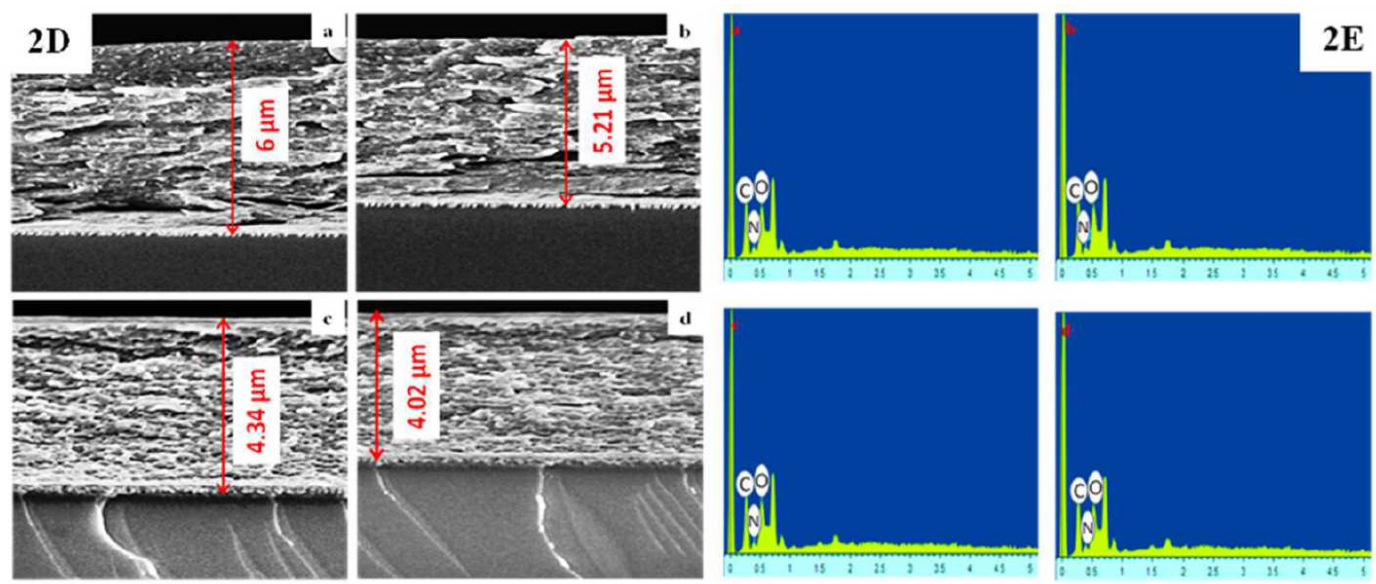

Figure 2D. FEs cross sections: a) $\mathrm{P}_{10}$, b) $\mathrm{P}_{20}$, c) $\mathrm{P}_{30}$ and d) $\mathrm{P}_{40}$. 2E. FEs EDX spectra: a) $\mathrm{P}_{10}$, b) $\mathrm{P}_{20}$, c) $\mathrm{P}_{30}$ and d) $\mathrm{P}_{40}$

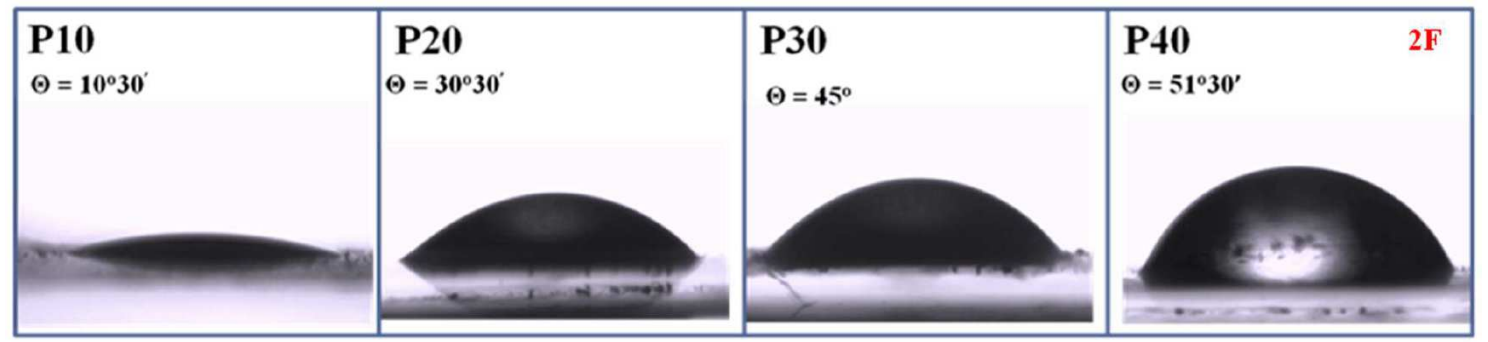

Figure 2F. Contact angle measurements for $\mathrm{P}_{10}, \mathrm{P}_{20}, \mathrm{P}_{30}$ and $\mathrm{P}_{40} \mathrm{FEs}$

\section{Electrochemical characterization}

\section{CV analyses}

All FEs were subjected to $\mathrm{CV}$ analyses within a potential window of $-1.2 \mathrm{~V}$ to $0.6 \mathrm{~V}$, at $5 \mathrm{mV} \mathrm{s}^{-1}$ (Fig. 3A). CV curves of all FEs showed broad peaks on the positive sweep of the potential, corresponding to PPy matrix doping with $\mathrm{NO}_{3}{ }^{-}$ anions, while the peak on the negative sweep of the potential corresponded to the PPy matrix de-doping (Scheme 2).

\section{Doping}

$$
\begin{gathered}
\mathrm{PPy}+\mathrm{NO}_{3}^{-} \longrightarrow \begin{array}{c}
\left(\mathrm{PPy}+\mathrm{NO}_{3}^{-}\right) \\
\text {complex }
\end{array} \\
\text { De-doping } \\
\begin{array}{l}
\left.\mathrm{PPy}+\mathrm{NO}_{3}^{-}\right) \\
\text {complex }
\end{array}
\end{gathered}
$$

Scheme 2. FE charge storage mechanism. 
The potential limits observed for the potential window are different from those observed in the literature [9]. This increase in the potential window is attributed to the $\mathrm{NaNO}_{3}$ electrolyte. Specific FEs capacitances (SC) were calculated by using the following equations [9, 11-12].

$$
\begin{array}{ll}
\text { Capacitance } & \mathrm{C}=\frac{\int_{v 1}^{v 2} I d v}{V \frac{d V}{d t}} \\
\text { Specific Capacitance } & \mathrm{SC}=\frac{C}{m}=\frac{\int_{v 1}^{v 2} I d v}{m(V) \frac{d V}{d t}}
\end{array}
$$

where $\mathrm{I}$ is the average current in the Redox cycle, $\mathrm{V}$ is the potential window, $\mathrm{dv} / \mathrm{dt}$ is the voltage scan rate, $\mathrm{C}$ is the capacitance, and $\mathrm{m}$ is the active material mass dipped in the electrolyte. Despite of the decrease in FEs thickness, it was found that $\mathrm{SC}$ gradually decreased with $\mathrm{I}_{\mathrm{t}}$, from $\mathrm{P}_{10}$ to $\mathrm{P}_{40}$ (inset of Fig. 3A). This may be due to the reduction in the material's globular size, making it less interactive for the electrolyte. The same has been corroborated by the wettability test. The measured $\mathrm{SC}$ was found to be maximum for $\mathrm{P}_{10} \mathrm{FE}$.

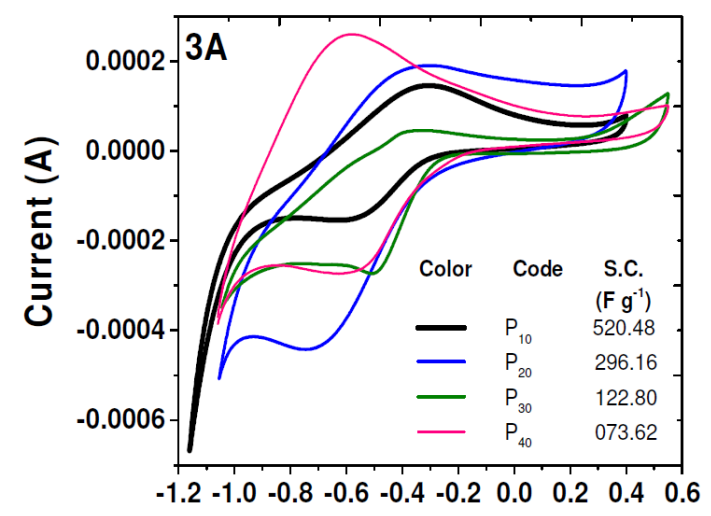

Potential V vs $\mathrm{Ag} / \mathrm{AgCl}(\mathrm{V})$

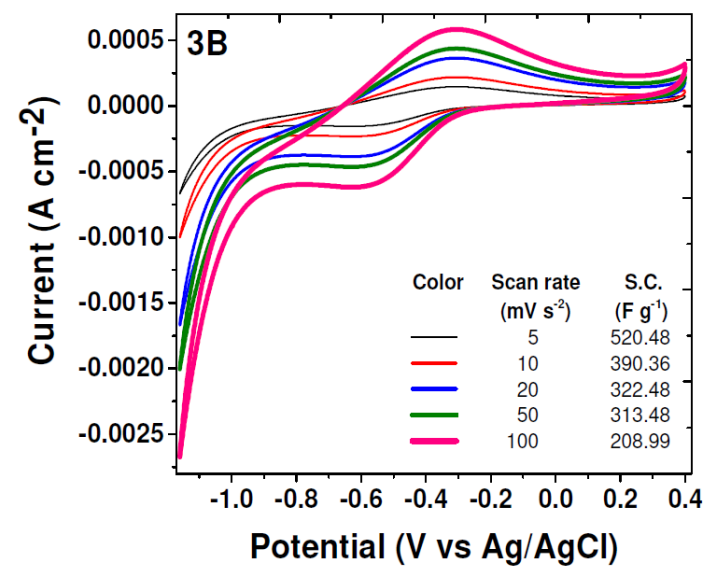

Potential ( $\mathrm{V}$ vs $\mathrm{Ag} / \mathrm{AgCl})$

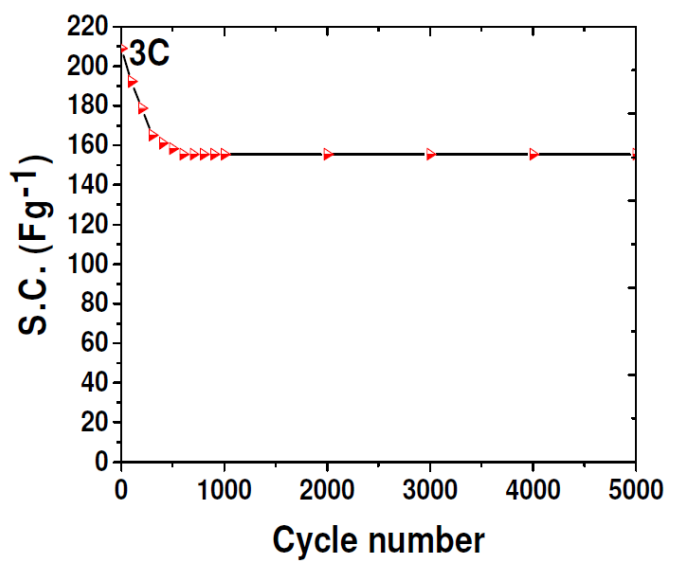

Figure 3. (A) Cyclic voltammograms of all FEs at $5 \mathrm{mVs}^{-1}$ in $0.5 \mathrm{M} \mathrm{NaNaNO}_{3}$; (B) $\mathrm{P} 10$ cyclic voltammograms in $0.5 \mathrm{M} \mathrm{NaNO}_{3}$, at different scan rates; (C) P10 cycling stability analysis of $100 \mathrm{mVs}^{-1}$ in $0.5 \mathrm{M} \mathrm{NaNO}_{3}$.

Potential scan rate variations have been applied $\left(5 \mathrm{mVs}^{-1}\right.$ to $\left.100 \mathrm{mVs}^{-1}\right)$ to $\mathrm{P}_{10} \mathrm{FE}$, and the consequences were observed. The peaks corresponding to the material's 
doping with anions tended to shift towards more positive potentials, while the peaks corresponding to the material's de-doping have shifted towards more negative potentials, with an increase in the scan rate. It was observed that, even though the current integral went on increasing with an increase in the scan rate, $\mathrm{SC}$ went on decreasing with the scan rate (Fig. $3 \mathrm{~B}$ ). FE $\mathrm{P}_{10} \mathrm{SC}$ was found to vary with the applied scan rate variations (inset of Fig. 3B). This is because the current integral did not increase in the same proportion as that of the scan rate. This may be due to the fact that the PPy matrix doping and de-doping rate with the $\mathrm{NO}_{3}{ }^{-}$anions did not vary in the expected proportion [11-13].

PPy suffers from poor elasticity in shape during the electrochemical reactions, affecting its cycling stability. The matrix could not regain the shape during the anionic doping-de-doping. $\mathrm{P}_{10}$ FE cycling stability study has been carried out at $100 \mathrm{mV} / \mathrm{s}$, to check its durability. There was SC loss by $9 \%$, at the end of the second cycle. This was due to the anions repulsion caused by the $\mathrm{NO}_{3}{ }^{-}$anions entrapment in the PPy matrix, as well as on its surface, during the first cycle. Rapid decrease in SC has been observed in 300 cycles, by nearly $20.98 \%$ of its original value. Then, it slowly decreased until the $600^{\text {th }}$ cycle, by $5.80 \%$. Afterwards, it decreased by $25.57 \%$ of its original value but, thereafter, it remained unaffected. Even after 5000 cycles, the $\mathrm{P}_{10} \mathrm{FE}$ showed $74.43 \%$ of capacitive retention, as the measured SC was $158.34 \mathrm{Fg}^{-1}$ (Fig. 3C).

\section{GCD analyses}

FEs galvanostatic charge-discharge (GCD) analyses were carried out within the potential window of $-1.4 \mathrm{~V}$ to $0.55 \mathrm{~V}$, at a constant current density of $0.2 \mathrm{mAcm}^{-2}$ (Fig. 3D). Unlike ideal capacitors, FEs exhibited a different GCD behavior. The charging curve showed an initial rapid charging, indicating the easy doping of $\mathrm{NO}_{3}{ }^{-}$anions in the PPy matrix, followed by exponential charging, demonstrating the opposition to the new $\mathrm{NO}_{3}{ }^{-}$anions, due to the pre-doped anions in the matrix.

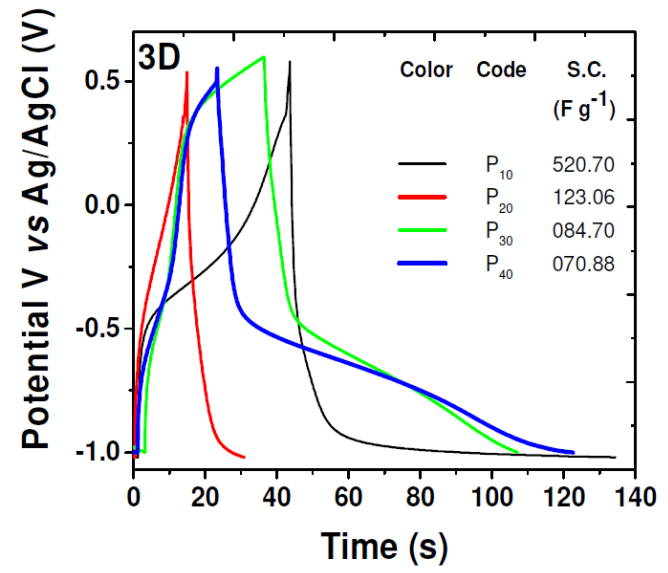

Figure 3D. GCD curves of all FEs in $0.5 \mathrm{M} \mathrm{NaNO}_{3}$, at $0.2 \mathrm{~mA} \mathrm{~cm}^{-2}$.

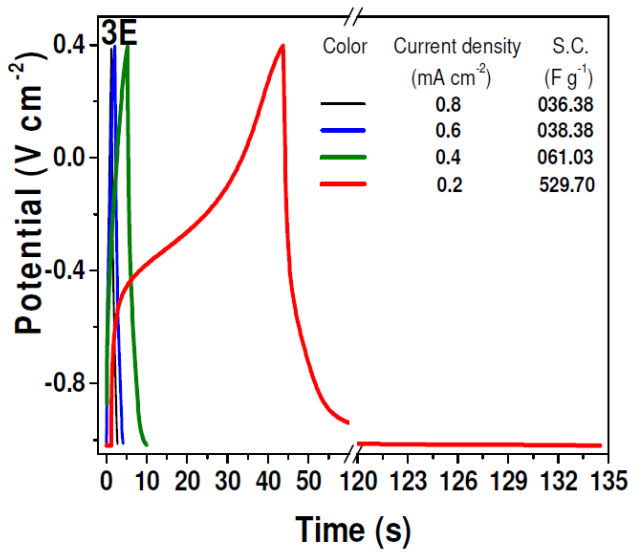

3E. $\mathrm{P}_{10} \mathrm{GCD}$ curves in $0.5 \mathrm{M} \mathrm{NaNO}_{3}$, at different current densities.

The discharging portion shows three parts, indicating an initial ohmic drop followed by a rapid discharging portion, which may be due to the rapid anions 
loss from the PPy matrix near to the surface and, finally, a time consuming exponential discharging portion, indicating a Faradaic charge storage [11-12].

$\mathrm{SC}$ values evaluated from the GCD curves are mentioned in the inset of Fig. 2D. As $\mathrm{P}_{10} \mathrm{FE}$ showed a maximum $\mathrm{SC}$ value $\left(520.70 \mathrm{Fg}^{-1}\right)$, it was subjected to the GCD analysis at different current densities (Fig. 3E), and it showed a slow discharging at lower current densities. The charging and discharging times went on decreasing with an increase in the current density. This may be due to the fact that the anionic doping and de-doping process rapidly occurred at higher current densities; hence, the total active material was not completely utilized [13].

Several chronopotentiometric parameters were calculated using the following equations $[9,11-12]$

$$
\begin{gathered}
\text { Specific capacitance }(S C)=\frac{I d \times t d}{V m} \\
\text { Specific energy }(S E)=\frac{V \times I d \times t d}{m} \\
\text { Specific power }(S P)=\frac{V \times I d}{m} \\
\text { Coulombic efficiency }(\eta)=\frac{t d}{t c} \times 100
\end{gathered}
$$

where $\mathrm{V}$ is the voltage, $\mathrm{I}_{\mathrm{d}}$ and $\mathrm{t}_{\mathrm{d}}$ are the discharging current and time, $\mathrm{m}$ is the active electrode mass and tc is the charging time. SE, SP and $\eta$ values, at various

\begin{tabular}{|c|c|c|c|c|}
\hline $\begin{array}{c}\text { Current density } \\
\left(\mathbf{I}_{d}\right) \\
\mathbf{m A c m}^{-2}\end{array}$ & $\begin{array}{c}\text { Specific capacitance } \\
(\mathbf{S C}) \\
\mathbf{F g}^{-1}\end{array}$ & $\begin{array}{c}\text { Specific energy } \\
\text { (SE) } \\
W^{-1} \mathbf{k g}^{-1}\end{array}$ & $\begin{array}{c}\text { Specific power } \\
\text { (SP) } \\
\text { kW kg-1 }\end{array}$ & $\begin{array}{c}\eta \\
(\%)\end{array}$ \\
\hline 0.2 & 529.70 & 395.55 & 15.5 & 42.99 \\
\hline 0.4 & 061.03 & 040.73 & 31.0 & 84.37 \\
\hline 0.6 & 039.87 & 026.60 & 46.5 & 96.26 \\
\hline 0.8 & 036.38 & 024.28 & 62.0 & 97.16 \\
\hline
\end{tabular}
current densities for FE, are reported in Table 2.

Table 2. Variations in the values of different chronopotentiometric parameters for $\mathrm{P}_{10}$, at different current densities in $0.5 \mathrm{M} \mathrm{NaNO}_{3}$.

\section{EIS analyses}

To study the electrode material's AC impedance at multiple frequencies, EIS analyses of all FEs have been carried out in the same electrolyte, within the frequency range from $5 \mathrm{mHz}$ to $100 \mathrm{kHz}$. Fig. 3F depicts the Nyquist plots along with the equivalent circuit nature, to evaluate different circuit parameters. The Nyquist plot consists of 2 regions, viz. low frequency region (Fig. 3F1) and high frequency region (Fig. 3F2). 


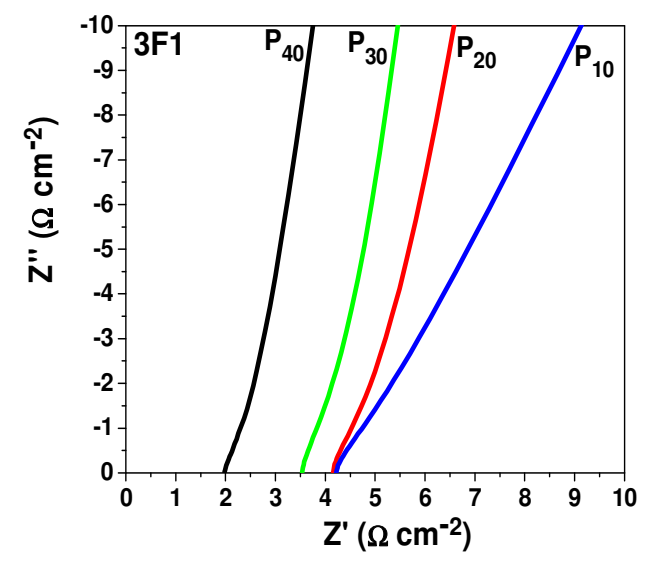

Figure 3F1. Nyquist plots for $\mathrm{P}_{10}, \mathrm{P}_{20}, \mathrm{P}_{30}$ and $\mathrm{P}_{40}$ in $0.5 \mathrm{M} \mathrm{NaNO}_{3}$ from EIS carried in the high frequency region.

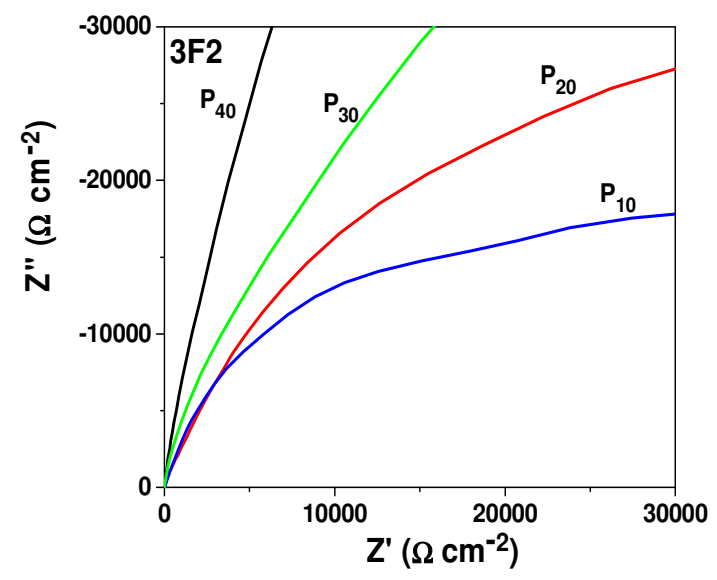

3F2. Nyquist plots for $\mathrm{P}_{10}, \mathrm{P}_{20}, \mathrm{P}_{30}$ and $\mathrm{P}_{40}$ in the whole frequency range from EIS carried in $0.5 \mathrm{M} \mathrm{NaNO}_{3}$, with the inset showing a typical equivalent circuit.

The plot intercept with the real axis in the high frequency region gives an equivalent series resistance (ESR or $R_{s}$ ), which is a combination of solution resistance, substrate-material interface resistance, ionic resistance and particle to particle contact resistance [34]. With the $I_{t}$ increase, the material became denser and, hence, the inter particle resistance decreased. Thus, the ESR $\left(\mathrm{R}_{\mathrm{s}}\right)$ value went on decreasing from $\mathrm{P}_{10}$ to $\mathrm{P}_{40}$. The lowest observed ESR value was $\sim 2.01 \Omega$, indicating a very low inter particle resistance, since the solution and substrates were the same. As there were extremely minute semicircles observed in the Nyquist plot at the high frequency region, the formed films were extremely adherent to the substrates [34]. The Nyquist plot slope in the mid frequency region gave the Warburg impedance $\left(R_{w}\right)$. $[9,12-13,31]$. With the increase in $I_{t}$, the material became less hydrophilic; thus, less accessible to the electrolyte. Hence, the Warburg impedance $\left(R_{w}\right)$ value went on increasing, and the ionic current went on decreasing with the $I_{t}$ increase. From $P_{10}$ to $P_{40}$, this causes an $R_{w}$ increase. These results are in perfect agreement with the previous works done on impedance and electrochemical analyses [32-33]. As the material became more hydrophobic and more resistive, the double layer charge storage went on increasing and, hence, the Nyquist plot inclination tended more towards the 
imaginary axis ( $Z$ "axis). A typical equivalent circuit for every FE shows similar circuit elements, but their values vary with the $\mathrm{I}_{\mathrm{t}}$ (Fig. 3G).

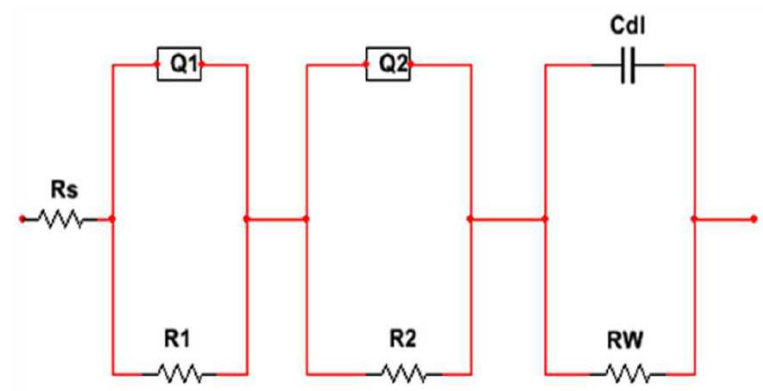

Figure 3G. Typical equivalent circuit for all FEs.

The evaluated parameters of circuit elements for different FEs are mentioned in Table 3.

Table 3. Different EIS parameters for FEs $\mathrm{P}_{10}, \mathrm{P}_{20}, \mathrm{P}_{30}$ and $\mathrm{P}_{40}$.

\begin{tabular}{cccc}
\hline $\mathbf{F E}$ & $\begin{array}{c}\mathbf{R}_{\mathbf{s}} \\
\text { (in } \mathbf{\Omega})\end{array}$ & $\begin{array}{c}\mathbf{C}_{\mathbf{d l}} \\
\text { (in } \mathbf{F})\end{array}$ & $\begin{array}{c}\mathbf{R}_{\mathbf{w}} \\
\text { (in } \mathbf{\Omega})\end{array}$ \\
\hline $\mathrm{P}_{10}$ & 4.20 & 0.0001781 & 0.2704 \\
$\mathrm{P}_{20}$ & 4.13 & 0.0007436 & 1.1190 \\
$\mathrm{P}_{30}$ & 3.54 & 0.0012811 & 1.6770 \\
$\mathrm{P}_{40}$ & 2.01 & 0.002336 & 4.1967 \\
\hline
\end{tabular}

The equivalent circuit shows some additional components. $\mathrm{Q}_{1}$ is the constant phase element (CPE) used in place of the double layer capacitance $(\mathrm{Cdl})$, since the semicircle is depressed. $\mathrm{Q}_{2}$ is $\mathrm{CPE}$, because of the FE non-ideal capacitive behavior in the low frequency region, due to the electrode's non homogeneous nature [33]. $\mathrm{R}_{1}$ may be the resistance of the barrier formed amid the conducting SS substrate and the conducting PPy, and $\mathrm{R}_{2}$ may be the resistance at the solid electrode-liquid electrolyte interface.
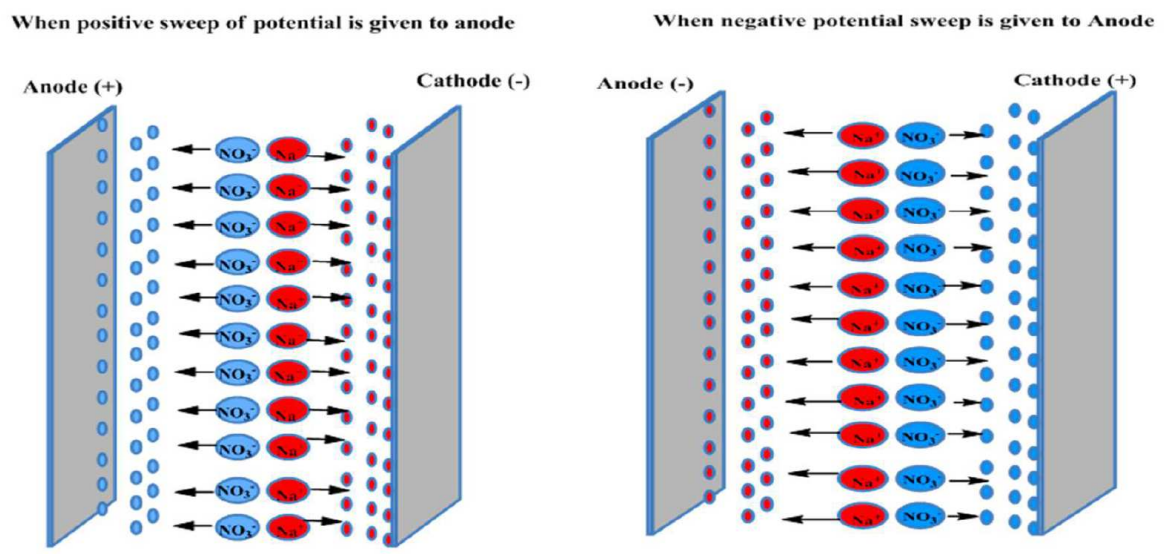

Figure 4A. SSD's pseudo-capacitive charge storage during cyclic voltammetry. 


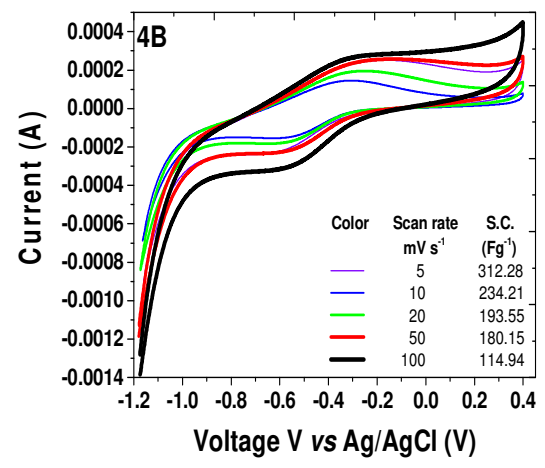

Figure 4B. Cyclic voltammetric study of prepared SSD.

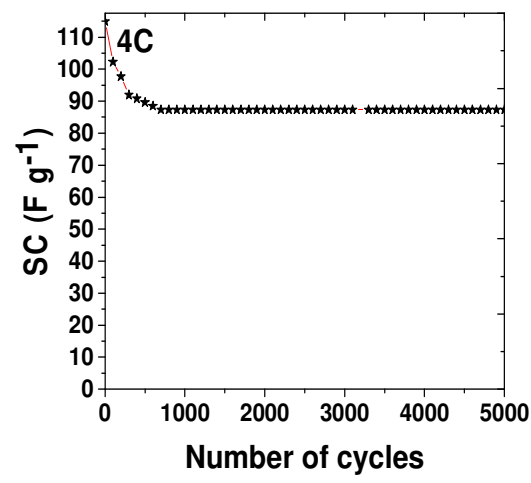

4C. Cycling stability curve for SSD.

\section{Cyclic voltammetric study of SSD}

The charge storage mechanism in SSD is also pseudo-capacitive.

When the positive potential sweep voltage is given to the anode, the anodic PPy matrix gets doped with $\mathrm{NO}_{3}{ }^{-}$anions, to form the complex. The charge is stored in the form of a complex, while $\mathrm{Na}^{+}$cations are adsorbed by the cathodic PPy. On the polarity reversal, the complexes are broken, and the ions are released into the electrolyte [Fig. 4A].

SSD showed a near symmetric pattern of CV curves [Fig. 4B]. There was a very slight variation in the potential limits, as compared to the individual FE. The current integral went on increasing with the scan rate. Further, a very slight peaks shifting, corresponding to the doping and de-doping, has been observed, indicating the material stability towards the current variation. SC values calculated from the CV curves for different scan rates, using formulae 1 and 2 , are mentioned in the inset of Fig. 3B. It was seen that SSD SC at $5 \mathrm{mV} / \mathrm{s}$ was $312.28 \mathrm{~F} \mathrm{~g}^{-1}$, which is nearly $60 \%$ of that of the individual $\mathrm{FE} \mathrm{P}_{10} \mathrm{SC}$. The plausible reasons for the SC fall are: (i) increased ionic resistance, due to the gel electrolyte formation, (ii) similar electrodes, and (iii) reduced electrolyte volume, etc.

\section{SSD cyclic stability}

SSD was subjected to a cycling stability study at $100 \mathrm{mV} \mathrm{s}^{-1}$. It was seen that SC decreased with an increase in the number of cycles, rapidly up to the first 300 cycles. SC at the $300^{\text {th }}$ cycle was $91.95 \mathrm{~F} / \mathrm{g}$, which was $80.04 \%$ of the original value. Thus, there was a SC loss of $19.96 \%$. Then, it slowly decreased until reaching 600 cycles, as it was $88.5 \mathrm{~F} / \mathrm{g}$, which indicates the further loss of only $3.75 \%$; thereafter, it remained unaffected, even after 5000 cycles [Fig. 4C], with nearly $76 \%$ of capacitance retention. 


\section{Conclusion}

The herein presented method is highly suitable for the binderless chemical synthesis of $100 \%$ pristine PPy in a simple way. FTIR spectra confirmed PPy formation. XRD confirmed PPy amorphous nature. With the increase in SILAR immersion time, FE surface morphology became denser, and less hydrophilic. Hence, FEs specific capacitance (SC) decreased. Slow discharging and large SC values of the prepared $\mathrm{FE}$, with $\mathrm{I}_{\mathrm{t}}=10 \mathrm{~s}$, prove its eligibility for high energy applications. The $\mathrm{NaNO}_{3}$ electrolyte has increased the potential window, as compared to the previously mentioned electrolytes. Though FE exhibited poor cycling stability, truly pristine FEs have been prepared. The fabricated SSD showed SC of $102.29 \mathrm{~F} / \mathrm{g}$ at $100 \mathrm{mV} / \mathrm{s}$, and $76 \%$ of capacitance retention, even after 5000 cycles. From overall results, it is concluded that the electrodes with less immersion time are suitable for high energy supercapacitors.

\section{Acknowledgement}

Authors are grateful to Solapur University, Solapur, India, for providing the DRF facility.

\section{References}

1. Conway BE. Electrochemical supercapacitors: scientific fundamentals and technological applications. New York: Kluwer-Plenum; 1999.

2. Dubal DP, Lee SH, Kim JG, et al. Porous polypyrrole clusters prepared by electropolymerization for high performance supercapacitor. J Mater Chem. 2012;22:3044.

3. Wang H, Hao Q, Yang X, et al. Effect of Graphene Oxide on the Properties of its Composite with Polyaniline. Appl Mater Interf. 2010;2:821.

4. Ambade RB, Ambade SB, Shrestha NK, et al. Polythiophene infiltrated $\mathrm{TiO}_{2}$ nanotubes as high-performance supercapacitor electrodes. Chem Comm. 2013;49:2308.

5. Thakur $\mathrm{AV}$, Lokhande $\mathrm{BJ} . \mathrm{C}_{10} \mathrm{H}_{8} \mathrm{~N}_{2}-\mathrm{PPy}$ hybrid flexible electrodes: synthesis and electrochemical study. J Mater Sci. 2018;29:1630.

6. Ambare RC, Bhardwaj SR, Lokhande BJ. Electrochemical characterization of $\mathrm{Mn}: \mathrm{Co}_{3} \mathrm{O}_{4}$ thin films by spray pyrolysis via aqueous route. Curr Appl Phys. 2014;14:1582.

7. Ambare RC, Bhardwaj SR, Lokhande BJ. Non aqueous route spray pyrolyzed $\mathrm{Ru}: \mathrm{Co}_{3} \mathrm{O}_{4}$ thin electrodes for supercapacitor applications. Appl Surf Sci. 2015;349:887.

8. Davies A, Audette P, Farrow B, et al. Graphene-Based Flexible Supercapacitors: Pulse-Electropolymerization of Polypyrrole on FreeStanding Graphene Films. J Phys Chem C. 2011;115:17612.

9. Shinde SS, Gund GS, Dubal DP, et al. Morphological modulation of polypyrrole thin films through oxidizing agents and their concurrent effect on supercapacitor performance. Electrochim Acta. 2014;119:1. 
10. Shi C, Zhitomirsky I. Electrodeposition and Capacitive Behavior of Films for Electrodes of Electrochemical Supercapacitors. Nanoscale Research Lett. 2010;5:518.

11. Thakur AV, Lokhande BJ. Dip time dependent SILAR synthesis and electrochemical study of highly flexible PPy: $\mathrm{Cu}(\mathrm{OH})_{2}$ hybrid electrodes for supercapacitors. J Solid State Electrochem. 2017;21:2577.

12. Thakur AV, Lokhande BJ. Effect of dip time on the electrochemical behavior of PPy $\mathrm{Cu}(\mathrm{OH})_{2}$ hybrid electrodes synthesized using pyrrole and $\mathrm{CuSO}_{4}$. e-Polymer. 2016;17:167.

13. Thakur AV, Lokhande BJ. Electrolytic anion affected charge storage mechanism of $\mathrm{Fe}_{3} \mathrm{O}_{4}$ flexible thin film electrodes in $\mathrm{KCl}$ and $\mathrm{KOH}$ : a comparative study by cyclic voltammetry and galvanostatic chargedischarge. J Mater Sci: Mater Electronics. 2017;16:11755.

14. Liu Z, Liu Y, Poyraz S, et al. Green-nano approach to nanostructured polypyrrole. Chem Comm. 2011;47:4421.

15. Tan Y, Ghandi K. Kinetics and mechanism of pyrrole chemical polymerization. Synthetic Metals. 2013;175:183.

16. Chen S, Zhitomirsky I. Capacitive behaviour of polypyrrole, prepared by electrochemical and chemical methods. Mater Lett. 2014;125:92.

17. Yin Z, Ding Y. CuO/polypyrrole core-shell nanocomposites as anode materials for lithium-ion batteries. Electrochem Comm. 2012;20:40.

18. Leonavicius K, Ramanavicius A. Polymerization Model for Hydrogen Peroxide Initiated Synthesis of Polypyrrole Nanoparticles. Langmuir. 2011;27:10970.

19. Piranha. University of Pennsylvania. Retrieved 4 May 2011.

20. Section 10: Chemical Specific Information - Piranha Solutions. Laboratory Safety Manual. Princeton University.

21. web.mit.edu/cortiz/www/PiranhaSafety.doc Standard Operating Procedure for Piranha Solutions - MIT. Retrieved 12 May 2016.

22. Procedure on handling and using Acid Piranha solution (PDF). University of Cambridge. Retrieved 12 June 2015.

23. Laboratory Procedures. Sci.chem FAQ. Retrieved 2008-01-11.

24. Seu KJ, Pandey AP, Haque F, et al. Effect of Surface Treatment on Diffusion and Domain Formation in Supported Lipid Bilayers. Biophys J. 2007;92:2445.

25. Piranha Waste Fact Sheet, University of Illinois at Urbana-Champaign.

26. An T, Cho SJ, Choi WS, et al. Soft Matter. 2011;7:9867.

27. Paul S. Polypyrrole Formation and Use, DRDC Atlantic TM 2005-004, January 2005.

28. Torabi M, Soltani M, Sadrnezhaad SK. Impedance Analysis of Growth and Morphology of Electropolymerized Polypyrrole Nanocomposites. J New Mater Electrochem Syst. 2014;17:129.

29. Ouyang JY, Li YF. Great improvement of polypyrrole films prepared electrochemically from aqueous solutions by adding nonaphenol polyethyleneoxy (10) ether. Polymer. 1997;38:3997. 
30. Cheah K, Forsyth M, Truong V-T. An XRD/XPS approach to structural change in conducting PPy. Synthetic Metals. 1999;101:19.

31. Lemon P, Haigh J. The evolution of nodular polypyrrole morphology during aqueous electrolytic deposition: influence of electrolyte gas discharge. Mater Research Bull. 1999;34:665.

32. Cheah K, Forsyth M, Truong V-T. Ordering and stability in conducting polypyrrole. Synthetic Metals. 1998;94:215.

33. Zheng LP, Wang Y, Wang XY, et al. J Mater Sci. 2010;45:6030.

34. Choudhari S, Bhattacharya D, Yu J-S. 1-Dimensional porous $\alpha \mathrm{Fe}_{2} \mathrm{O}_{3}$ nanorods as high performance electrode material for supercapacitor RSC Adv. 2013;3:25120. 